\title{
Enzyme-linked immunosorbent assay for brucella antigen detection in human sera
}

\author{
H. A. AL-SHAMAHY and S. G. WRIGHT \\ Department of Clinical Sciences, London School of Hygiene and Tropical Medicine, Keppel Street, London \\ WC1E 7HT and Central Health Laboratory, Ministry of Health, Sana'a, Yemen
}

\begin{abstract}
A sandwich enzyme-linked immunosorbent assay (ELISA) with monoclonal antibody coupled to the solid phase was evaluated for the detection of brucella antigen in serum samples. Under optimum conditions, 100 brucella cells $/$ well or $10^{5} \mathrm{fg} / \mathrm{ml}$ of lipopolysaccharide (LPS) were detected in spiked specimens. The standardised assay was performed on 1607 sera from random blood donors, 146 patients with brucellosis, 20 persons in high risk groups and 264 sera from patients with diseases other than brucellosis. Sensitivity was $100 \%$ compared with positive blood culture, and $44 \%$ compared with serological tests for brucella antibodies. Specificity was $99.5 \%$ among random blood donors and $99.2 \%$ in the patient population. These data showed a strong agreement between ELISA antigen detection and blood culture for the detection of brucella positive blood samples. Moreover, the results indicated that antigen detection by ELISA could be an acceptable alternative to blood culture for the diagnosis of brucellosis.
\end{abstract}

\section{Introduction}

The procedures most frequently used for the serodiagnosis of brucellosis are the rapid slide agglutination test (RSAT), standard tube agglutination test (SAT), 2mercaptoethanol tube agglutination test (2ME), complement fixation test (CFT) and enzyme-linked immunosorbent assay (ELISA).

One major problem in serodiagnosis is the crossreactions that occur between brucellae and other bacteria. A second problem is that a diagnosis of brucellosis cannot be established on the antibody titre alone, as healthy people connected with animal husbandry in endemic areas may show significant titres of brucella antibodies [1-3].

The third problem is that classical serodiagnosis does not distinguish acute cases from chronic ones $[4,5]$. ELISAs have been developed [6] which distinguish acute cases with elevated IgM from chronic cases with high IgG in the absence of IgM.

Received 24 Oct. 1996; revised version accepted 12 June 1997.

Corresponding author: Dr H. A. Al-Shamahy.

Present address: Department of Medical Microbiology, Faculty of Medicine and Health Sciences, Sana'a University, PO Box 775, Sana'a, Republic of Yemen.
During the past several years a concerted effort has been made to develop methods for brucella antigen detection. These methods were evaluated with spiked specimens, bovine vaginal secretions, plasma and urine of mice infected with brucella and blood samples from patients with brucellosis.

The aim of this study was to develop a sensitive and specific ELISA for brucella antigens, and to apply it under field conditions in Yemen for the detection of whole organisms or soluble antigens in human serum.

\section{Materials and methods}

\section{Reagents}

Mouse monoclonal antibodies (MAbs) to Brucella abortus A-epitope and B. melitensis M-epitope were kindly provided by Professor J.T. Douglas, Department of Microbiology, University of Hawaii, USA. Rabbit polyclonal antibody to $B$. abortus was obtained from Difco Laboratories, Detroit, Michigan, USA. Goat antirabbit IgG Fab conjugated to horseradish peroxidase was obtained commercially from Sigma Chemical Co. B. abortus BBS50 641 and B. melitensis BBS50 642 concentrated $O$ suspensions were from the Central Public Health Laboratory, 61 Colindale Avenue, London NW9. Lipopolysaccharides (LPSs) were extracted by the water-phenol procedure described for $B$. melitensis and B. abortus [7]. 


\section{Control sera}

For the positive control, a suspension of $10^{4}$ organisms $/ \mathrm{ml}$ was prepared by adding $B$. melitensis BBS50 642 suspension to pooled normal human serum collected from healthy persons and shown to be negative for brucella antibodies. For the negative control, a pool of negative control sera from healthy donors was selected for inclusion with each assay run.

\section{Blood donor and patient sera}

Sera were obtained from healthy blood donors $(\mathrm{n}=1607)$, patients with clinically diagnosed brucellosis who had a SAT titre of $\geqslant 320$ or were blood culture positive for B. melitensis, or both $(\mathrm{n}=146)$, patients with diseases other than brucellosis (including leukaemia, typhoid fever, malaria, kala-azar, rheumatoid arthritis, hepatitis A, hepatitis B, toxoplasmosis, tuberculosis, pyrexia of unknown origin) and patients with blood cultures positive for organisms other than brucellae $(n=264)$, and healthy veterinarians and veterinary laboratory workers $(n=20)$.

All specimens were stored below $-20^{\circ} \mathrm{C}$ until tested.

\section{ELISA procedure}

The assay was performed with disposable polystyrene micro-ELISA plates. Volumes of $100 \mu \mathrm{l}$ of mouse MAbs to $B$. abortus A epitope previously diluted in coating buffer $(5 \mu \mathrm{g} / \mathrm{ml})$ were used to coat each well overnight at $4^{\circ} \mathrm{C}$ in a humid chamber. The plates were then washed three times by emptying the plates and refilling all the wells with PBS-Tween 20 (PBS-T), leaving for $2 \mathrm{~min}$ and then removing by suction. A volume of $100 \mu \mathrm{l}$ of fetal calf serum $2 \%$ in PBS-T was added to each well to block any remaining proteinbinding sites and the plates were incubated at room temperature for $1 \mathrm{~h}$. The plates were then washed as described above. A volume of $100 \mu \mathrm{l}$ of test serum, positive or negative control or blank was added and the plates were incubated overnight at $4^{\circ} \mathrm{C}$ in a humid chamber. They were then washed as described above. Diluted rabbit polyclonal antibody to $B$. abortus $(100 \mu \mathrm{l} ; 1$ in 500 in PBS-T20 containing calf fetus serum $2 \%$ ) was added to each well and incubated at $37^{\circ} \mathrm{C}$ for $2 \mathrm{~h}$. The unbound antibodies were washed off and $100 \mu \mathrm{l}$ of peroxidase-antibody conjugate at a dilution of 1 in 1000 were added and incubated at room temperature for $1 \mathrm{~h}$. The unbound conjugate was washed off and $100 \mu 1$ of $o$-phenylene-diamine dihydrochloride (OPD) substrate solution at a concentration of $0.4 \mathrm{mg} / \mathrm{ml}$ were added and the plate was left in the dark at room temperature for $25 \mathrm{~min}$ for the colour to develop. Finally the reaction was stopped by adding $25 \mu \mathrm{l}$ of $2.5 \mathrm{M} \mathrm{H}_{2} \mathrm{SO}_{4}$ to each well. The colour reaction was measured in an ELISA reader. The concentration of the brucella antigen was expressed as absorbance measured at $492 \mathrm{~nm}$.
The optimum concentration of different components was determined by chequer-board titration, first with a wide range, and subsequently small dilution increments around the optimum.

The validity of the test was assessed by including a full set of controls (including substrate control) on each plate and the values of each control for each run were charted, as a quality control exercise: the Shewhart method [8, 9] was used. The cut-off value was calculated with reference to negative sera. Cut-off was based on 2.1 times the mean absorbance value of the negative control.

\section{Results}

At present there is no recognised standard for establishing the presence or absence of brucella antigen in human blood. Therefore, the relative sensitivity of the technique was established by using whole organisms in various dilutions and using B. melitensis LPS. Each dilution was assayed in replicates of three for 3 days with the same batch of material. The mean sensitivity detected for the procedure was 100 organisms/well and $10^{5} \mathrm{fg}$ of $\mathrm{LPS} / \mathrm{ml}$.

In clinical specimens the sensitivity of the test was determined from the results of tests on patients with brucellosis confirmed by blood culture, or serodiagnosis, or both. Sensitivity was $100 \%$ compared with positive blood culture, and $44 \%$ when compared with serological tests for brucella antibodies (Table 1).

In clinical specimens the specificity of the test was determined from the results of tests on random sampled blood donor populations, patients with other diseases and persons in occupations which exposed them to a high risk of contracting brucellosis. Specificity was $99.5 \%, 99.2 \%$ and $100 \%$ respectively (Table 1).

Comparing the patient group and the control groups, higher scores of ELISA were found with confirmed brucellosis than control samples from a patient population with other diseases $\left(p<0.001, \chi^{2}\right.$ Yates corrected $=126$; Table 1 ). In addition, patients with confirmed brucellosis had higher ELISA scores than did control samples from random blood donor populations $\left(\mathrm{p}<0.001, \chi^{2}\right.$ Yates corrected $=388$; Table 1).

\section{Evaluation of antibiotic therapy}

When sera from post-therapy brucellosis patients $(\mathrm{n}=16)$ were analysed by ELISA for antigen detection, absorbance values were observed to have declined. This suggested removal of organisms from the circulation following treatment. All patients who were initially reactive were negative after they had received therapy 
Table 1. Detection of brucella antigen in serum samples from confirmed brucellosis patients (blood culture positive), brucellosis cases diagnosed clinically and serologically, patients with diseases other than brucellosis and healthy blood donors

\begin{tabular}{lccc}
\hline & \multicolumn{3}{c}{ Number of specimens } \\
\cline { 2 - 4 } Subject group & tested & initially reactive & repeatable reactive (\%) \\
\hline Brucellosis cases $^{\dagger}$ & 13 & 13 & $13(100)$ \\
Brucellosis cases $^{\dagger}$ & 133 & 56 & $51(38.3)$ \\
Total brucellosis cases & 146 & 69 & $64(44.0)$ \\
High risk group & 20 & 0 & $0(0)$ \\
Miscellaneous diseases & 264 & 3 & $2(0.7)$ \\
Blood donors & 1607 & 47 & $43^{\ddagger}(2.6)$ \\
\hline
\end{tabular}

*Blood culture positive.

${ }^{\dagger}$ Blood culture negative.

${ }^{\ddagger}$ Thirty-six were confirmed positive by brucella SAT.

with rifampicin and co-trimoxazole, doxycycline and rifampicin, or doxycycline alone for $c .1$ month. There was no opportunity to assess the value of the test in detecting relapses.

\section{Discussion}

Brucellosis is still a major health problem worldwide $[1,2,3]$. Numerous studies have been carried out in various laboratories to obtain better methods of diagnosis [10-13].

This study presents data on the development and optimisation of an ELISA-based technique to detect $B$. melitensis and $B$. abortus antigens directly in spiked serum specimens, and in clinical specimens from patients with brucellosis. The results obtained when this test was applied to serum samples from blood donors, patients with brucellosis diagnosed clinically, serologically or bacteriologically, in persons in high risk groups, and in patients with diseases other than brucellosis, indicate the possible advantages of using sensitive and specific MAbs to $B$. abortus A epitope or B. melitensis M-epitope for antigen detection (Table 1). The assay enabled the detection of brucella antigen in patients with brucellosis confirmed by blood culture. Because of the nature of the sample (positive blood culture for $B$. melitensis), it could be argued that the test appeared to be $100 \%$ sensitive, but the major point against this argument was the small number of sera tested.

The failure to detect antigen in $56 \%$ of clinical samples from patients who were diagnosed clinically and serologically as having active brucellosis might have been due to the prior use of antibiotics or delay in collection of blood.

The presence of brucella-specific antibodies in patient serum did not interfere with the detection of brucella antigen. Possibly the presence of immune complexes in serum does not affect the accessibility of the epitope on the Brucella cell wall recognised by Mepitope MAb and A-epitope MAb. Human antibodies produced against brucella antigen after natural infections may recognise epitopes other than those recognised by the MAbs.

Bacterial counts in patients with gram-negative bacteraemic infections such as typhoid fever are low $(10-20 \mathrm{bacteria} / \mathrm{ml})$ [14]. This value is 100 times lower than the limit of detection of the described ELISA with whole bacteria diluted in normal human serum, suggesting that this assay detects antigenaemia rather than bacteraemia during the acute phase of brucellosis.

Observations from the present study indicate that the time of collection of the sample and prior use of antibiotics are important parameters in the evaluation of the test. A significant decrease in absorbance value was found 6-10 weeks after the onset of the disease, and in patients who had previously used antibiotics. In general, successful treatment decreased or eliminated the antigen from blood samples.

The strong agreement between ELISA antigen detection and blood culture when applied to brucellainfected blood samples suggested that the former method may be an acceptable alternative to cultural isolation for the diagnosis of brucellosis. The results of this study are only preliminary and are based on a small number of blood culture positive and serology positive samples. Further work should be done to establish the clinical efficacy of the test.

I thank Drs D. Bidwell and A. Voller from LSH \& TM and the Institute of Zoology in London for their expert advice, supervision and help with the ELISA techniques. Special thanks go to Dr M.H. Al-Fadeel, Mr Al-Asta and Mr Entessar Al-Domany all from the Central Health Laboratory, Sana'a, Yemen, and T. Mackintosh Smith for their great help and co-operation given to me during the field work. I am pleased to acknowledge the Overseas Development Agency and the British Council for their help and financial support. 


\section{References}

1. Zourbas J, Masse L, Roussey A, David C, Maurin J, Torte J. Sampling survey on brucellosis among farmers and their families in Ille-et-Vilaine (Brittany). Int $J$ Epidemiol 1977; 6: 335-343.

2. Gilbert GL, Beaton CP, Forsyth JR, Bell CO. An epidemiological survey of human brucellosis in three Victoria abattoirs. Med J Aust 1980; 1: 482-486.

3. Ramanna BC, Srivastava L, Suri JC, Sharma RS, Dutta KK. A seroepidemiological study of brucellosis in rural and urban population of north India. J Commun Dis 1982; 14: 281-285.

4. Corbel MJ. Identification of the immunoglobulin class active in the Rose Bengal plate test for bovine brucellosis. J Hyg 1972; 70: 779-795.

5. Díaz R, Maravi-Poma E, Rivero A. Comparison of counterimmunoelectrophoresis with other serological tests in the diagnosis of human brucellosis. Bull World Health Organ 1976; 53: 417-424.

6. Wreghitt TG, Morgan-Capner P. ELISA in the clinical microbiology laboratory. London, Public Health Laboratory Service. 1990.

7. Leong $\mathrm{D}$, Diaz $\mathrm{R}$, Wilson. Identification of the toxic component of Brucella abortus endotoxin and its labelling with radioactive chromate. $J$ Bacteriol 1968; 95: 612-617.

8. Levey S, Jennings ER. The use of control charts in the clinical laboratory. Am J Clin Pathol 1950; 20: 1059-1066.

9. Westgard JO, Barry PL, Hunt MR, Groth TMA. A multi-rule Shewhart chart for quality control in clinical chemistry. Clin Chem 1981; 27: 493-501.

10. Chen IM, Thoen CO, Pietz DE, Harrington R. Application of an enzyme-linked immunosorbent assay for detection of Brucella antigen in vaginal discharge of cows. Am J Vet Res 1984; 45: 32-34.

11. Limet JN. Immunoassay of Brucella lipopolysaccharide-derived antigen in plasma: a new method of diagnosis. Ann Inst Pasteur Microbiol 1987; 138: 126-130.

12. Geraci D, Locorotondo G, Parlato A et al. Enzyme-linked immunosorbent assay for Brucella melitensis-associated antigens. Microbiologica 1988; 11: 213-218.

13. Fekete A, Bantle JA, Halling SM, Sanborn MR. Preliminary development of a diagnostic test for Brucella using polymerase chain reaction. $J$ Appl Bacteriol 1990; 69: 216-227.

14. Sadallah F, Brighouse G, Del Gindice G, Drager-Dayal R, Hocine M, Lambert PH. Production of specific monoclonal antibodies to Salmonella typhi flagellin and possible application to immunodiagnosis of typhoid fever. $J$ Infect Dis 1990; 161: $59-64$. 